\title{
La actitud económica de la burguesía en la España del siglo XVIII
}

\author{
Pere Molas Ribalta *
}

Conviene comenzar esta exposición con unas consideraciones sobre el concepto y divisiones de la burguesía ${ }^{1}$. De ordinario se identifica burguesía con actividad mercantil, y realmente el comercio constituía, todavía en el siglo XVIII, la principal base de ingresos de la burguesía. Pero debemos llamar la atención sobre la importancia de las profesiones liberales. Médicos y hombres de leyes tuvieron gran importancia en el movimiento ideológico y cultural de la centuria. Más aún el desarrollo económico de un país daba lugar al desarrollo de las profesiones y al beneficio económico de la abogacía, por ejemplo, como puede constatarse en Inglaterra ${ }^{2}$. El lector se habrá encontrado con las expresiones burguesía agraria o burguesía rural en obras sobre el siglo XVIII español. Se refieren a los propietarios campesinos no nobles, pero de gran importancia en los pueblos, llamados en la época "los poderosos".

La burguesía mercantil del Antiguo Régimen obtenía una parte de sus beneficios en colaboración con la monarquía absoluta y los estamentos privilegiados. Los arrendatarios de derechos señoriales y de diezmos, el arrendamiento de impuestos, los «asientos" o contratos de suministros estatales, sobre todo militares (de alimentación, vestuario, transporte, etcétera). Los contratos de abastos e impuestos municipales eran campo de acción de los grandes comerciantes. Así lo vemos en la burguesía de

* Universidad Central de Barcelona.

' Pere Molas Ribalta: La burguesia mercantil en el Antiguo Régimen, Madrid 1985, pp. 17 y ss.

${ }^{2}$ Peter MATHIAS: The lawyer as businessman, comunicación presentada en la XIV Settimana del Prato, 1982. 
Barcelona a fines del $x \mathrm{VII}^{3} \mathrm{y}$ a lo largo del siglo $\mathrm{XVIII}{ }^{4}$. A partir de 1750 en la Cataluña interior la familia Cortadellas, radicada en la villa de Calaf (una villa de señorio de los Cardona-Medinaceli) realizó negocios de centenares de miles de libras en arrendamientos de derechos señoriales y diezmos ${ }^{5}$. Los Cinco Gremios Mayores de Madrid, gran compañía capitalista de base corporativa, realizó buena parte de sus beneficios en los contratos estatales, los arrendamientos de impuestos y de diezmos destinados al Estado y el suministro de la Villa y Corte ${ }^{6}$. En La Coruña se ha observado la existencia de unos comerciantes al estilo tradicional, creados al amparo del arriendo de arbitrios y abastos. A mayor abundamiento en una ciudad interior, como Santiago de Compostela, se encontraba una burguesía inmovilista en lo económico y tradicional en su mentalidad, a la cual el arrendamiento de impuestos, los negocios realizados con la administración, colocaban en la vía del ennoblecimiento ? Los mismos comportamientos se encuentran entre los comerciantes sevillanos $^{8}$. También para Francia se ha destacado la imbricación de los comerciantes con los contratos estatales y los arrendamientos de impuestos: se la ha designado como una "burguesía de finanzas" ${ }^{9}$. Veremos más adelante que la burguesía española del XVIII no realizó grandes avances en el sector financiero. Un ejemplo, en parte tradicional lo tenemos en Pedro Vicente Galabert, comerciante de origen francés arraigado en Valencia, cuñado de Cabarrús, comerciante de origen francés, contratista del Estado, en provisiones militares y a la vez vinculado a la política

${ }^{3}$ Pere Molas Ribalta: Comerç i estructura social a Catalunya i Valencie als segles xvil i xvm, Barcelona 1977, pp. 150-151, 154-155.

4 Pierre VILAR: Catalunya dins l'Espanya Moderna, Vol. IV. La formació del capital comercial. Barcelona 1968, IV. p. 268 y 429 y ss. A. MOLAS RiBAL, Comerc, op cit, pp. $256-$ 257 y 289-290. También "Els arrendaments publics a la Barcelona del set-cents", en Cuadernos de Historia Económica de Cataluña, VI, 1971, pp. 89-111.

Véase los articulos publicados sobre el tema en las Actas del / Congrès d'Historia Moderna de Catalunya, Barcelona 1984.I.

- Capella. Matilla Tascón. Los Cinco Gremios Mayores de Madrid, Madrid 1957.

Antonio EIRAS RoEL: "La burguesía mercantil compostelana a mediados del siglo XVIII en La Historia Social de Galicia según fuentes de protocolos, Santiago 1981, pp. 521-564.

${ }^{8}$ Pierre PONSOT: "A la recherche d'une famille d'homme d'affaires sevillans de XVIII siècle Les Cociella, en II Jornadas de Metodologia Aplicada de las Ciencias Históricas, Santiago 1981, I 105-115. Alvarez Santalo y Garcia Baquero, "Funcionalidad del capital andaluz en visperas de la primera industrialización, en Estudios Regionales, número 5, pp. 101-133.

9 J. L. Bourseon: Les Colbert avant Colbert. Destin d'une famille merchande. Paris 1973. Obviamente se refiere a una situación anterior a 1650. Posteriormente se formó el grupo de los arrendatarios colectivos de los impuestos indirectos conocidos como "Les cinq grandes fermes", Yves DuRAND: Les fermiers generaux en France au XVIII siècle. Paris 1971. 
financiera de fines de siglo ${ }^{10}$. Han sido estudiados los asentistas vascos y navarros (como los Goyeneche y otros) vinculados a la administración de hacienda del Estado ${ }^{11}$.

La burguesia era también propietaria agraria. La propiedad de la tierra constituia una parte importante de las fortunas burguesas. Citaremos algunos ejemplos relativos a Cataluña. Vilar ha reunido muchos datos de los intereses agrarios de los comerciantes de Barcelona ${ }^{12}$. Tenemos también datos relativos al activo puerto de Mataró. En el inventario de Joseph Centallops (1773), comerciante e industrial, figuraban diez piezas de tierra ${ }^{13}$.

Hablar de la actividad económica de la burguesía significa referirse al comercio y a las ciudades. A diferencia de lo que acontecia en el siglo $\mathrm{XVI}$, las ciudades más activas y más densamente pobladas se hallaban situadas en el litoral peninsular: mediterráneo, andaluz y cantábrico. La España interior presentaba una escasa vitalidad urbana y mercantil. En Toledo, a mediados de siglo, el estudio de la sociedad abarca fundamentalmente a nobleza, artesanos, criados, jornaleros y pobres ${ }^{14}$. Sin destacar a los débiles grupos burgueses, que sin duda existían ("mercaderes de escritorio", "mercaderes de calle ancha", compañía de "comercio y fábricas" en 1748) ${ }^{15}$. Muchas ciudades de Castilla la Vieja ofrecian una situación de atonía económica. En Avila, a fines de siglo, existía poco consumo de productos de calidad. El consumo se dividia en tres niveles: 1) ganaderos y agricultores, "que es la general ocupación", 2) los eclesiásticos que constituian el «mayor número de habitantes de conveniencia" y 3) un grupo minoritario de propietarios agricolas; estos tres niveles se surtian respectivamente de la producción local, de la regional (segoviana) y de la nacional ${ }^{16}$. Burgos, gran centro del comercio internacional castellano en el siglo xvi, no logró superar su estancamiento, a pesar de la protección oficial. «No hay en Burgos gran copia de comerciantes verdaderos", sentenciaba a fines de siglo Eugenio de Larruga. Las propias

10 MOLAS: Burguesia... 218-219, y Comerc, 253-259.

J. Caro Baroja: Las hora navarra del siglo xvil. Pamplona 1969 (2. edición, 1985)

12 Pierre VILAR: Catalunya dins l'Espagna moderna, III, Barcelona 1966, 276-278.

13 Molas Ribalta: Societat i poder politic a Mataró 1718-1808, Mataró 1973, pp. 21-44.

14 JIMENEZ DE GREgorio: Toledo a mediados del XVIII. Economia, Sociedad y Administración. Toledo 1959.

${ }^{15}$ Eugenio de LaRruga: Memorias políticas y económicas sobre los frutos, comercio, fábricas y minas de España, Tomo VII, Madrid 1790.

${ }^{16}$ lbidem, Tomo XX, pp. 45-46. 
ordenanzas del consulado de 1766 reconocían que predominaba en Burgos

el comercio que hace por menor el trato de paños y sedas y el de joyería ${ }^{17}$.

Los gremios mayores de las ciudades de Castilla reconocían la diferencia cuantitativa y cualitativa de su comercio con relación al de Madrid, "por no haber la copia de mercaderes y compradores" ${ }^{18}$.

La Villa y Corte constituía un gran centro consumidor de productos de primera necesidad y de mercancias de lujo. Se ha estudiado $-y$ enfatizado - la posible distorsión que supuso la creciente demanda de una capital nacional sobre el mercado regional de Castilla la Nueva, y aún sobre toda la red urbana de la España interior ${ }^{19}$. A principios del síglo XIX, los cinco gremíos mayores, que se dedicaban primordialmente al comercio de tejidos, especies y joyas, reunian unos 300 individuos, a los que habia que unir una activa minoria de banqueros, financieros y asentistas $^{20}$.

En el litoral mediterráneo destaca la expansión de Barcelona que triplicó su población, llegando a los 100.000 habitantes. El crecimiento mercantil de Barcelona se debió a la potenciación de distintos mercados: 1) el mercado interior catalán, 2) el mercado tradicional mediterráneo, 3) el mercado interior peninsular y 4) el comercio con América ${ }^{21}$. La nueva burguesía surgida en el siglo xvIII encontró su plasmación institucional en la matrícula de comercio, formada en 1758 e integrada por 41 comerciantes matriculados, a los que se unieron otros 41 en una segunda promoción ${ }^{22}$. Habia además cierto número de comerciantes, de menor

17 Ibidem, Tomo XXVIII y XXIX. MOLAS: Burguesia, 247-260. Según el Almanack Mercantil de 1806 existian en Burgos un total de 54 comerciantes.

${ }^{18}$ Molas: Burguesía 105.

19 David Ringrose: Madrid 1560-1850, Madrid 1985.

20 Almanack Mercantil o Guia del Comerciante. Madrid 1806, p. 410.

${ }^{21}$ Un ejemplo de comerciante catalán del xvill que cubria los citados ámbitos es el de Bernardo Gloria estudiado por R. FERnÁndez, en la obra coordinada por Pedro TEDDE: La economía española al final del Antiguo Régimen, Il Manufacturas, Madrid 1982. Para el comercio con América, Martinez SaW: Cataluña en la Carrera de Indias. 1680-1756, Barcelona 1981.

22 MOLAS: Comerç... p. 276-277. 
entidad, que no pertenecian a la matrícula pero que ejercían libremente el comercio.

La vitalidad de Barcelona estaba acompañada por la de otras ciudades, fundamentalmente litorales, o cercanas al mar, en las que confluían la producción vitícola, el comercio marítimo y el desarrollo de una industria textil. Mataró en la comarca del Maresme ${ }^{23}$, y Reus en la del Baix Campo constituyen los mejores ejemplos. A principios del siglo XIX numerosas poblaciones del litoral catalán contaban con una nutrida representación mercantil y lo mismo sucedía en algunas del interior con vocación industrial como Olot y Manresa.

En el reino de Valencia es bien conocida la importancia del puerto de Alicante ${ }^{24}$, ciudad que según los datos del Almenack Mercantil contaba con un centenar de comerciantes de diversa categoría a principios del siglo $x \mid x^{25}$. La relevancia del comercio de la ciudad de Valencia ha sido destacada por una tesis reciente ${ }^{26}$. De esta tesis se desprende la existencia en la capital de aquel reino de una nutrida burguesía mercantil, que disponía de grandes capitales; esta burguesía, fue más autóctona de lo sugerido por la frecuencia de algunos apellidos extranjeros, y también menos vinculada a la industria sedera de lo que se había supuesto. El Almanack Mercantil relaciona 167 comerciantes.

En Sevilla el número de comerciantes incluidos en el consulado nuevo fundado en 1785 superaba el centenar. Estudios recientes muestran el elevado grado de capitalización de la burguesía mercantil sevillana, pero también el carácter tradicional de sus inversiones ${ }^{27}$. Málaga se desarrolló en el siglo XvIII. En el Almanack de 1806 se contabilizaban 54 comerciantes al por mayor. Era importante la colonia de comerciantes de origen extranjero, en buena parte exportadores de la producción agraria ${ }^{28}$, organizados en torno a la institución del “alto comercio marítimo».

23 MOLAS: Societat i poder politic.

${ }^{24}$ Enrique JIMENEZ LOPEZ: Alicante en el siglo xvII, Valencia 1981.

${ }^{25}$ Almanack Mercantil o Guie del Comerciante, pp. 385 (Mataró), 389 (Vic), 390 (Vilanova), 392 (Tarrasa), 393 (Valls), 395 (Sabadell), 398 (Areyns), etc.

${ }_{26}^{6}$ R. Franch: La burguesía comercial valenciana en el siglo xvil, (1985). Véase una sintesis anterior en MOLAS: La burguesia, pp. 209 y ss.

27 Álvarez Santalo y Garcia Baquero: c.i.

${ }^{28}$ Begoña VILLAR: Los extranjeros en Málaga en el siglo XVII.Málaga 1982. 
Cádiz fue durante la mayor parte del siglo la capital del comercio con América. Treinta años después de haberse ampliado la posibilidad de comercio con América a diversos puertos peninsulares (1778), todavía destacaba con 488 comerciantes al por mayor, 21 compañias de seguros, 61 corredores de lonja y 14 cónsules extranjeros. Autores del siglo XVIII e historiadores del siglo $x x$ coinciden en destacar el carácter conservador $y$ poco innovador de la burguesía gaditana. Se trataba fundamentalmente de comerciantes a comisión, cuyos beneficios no transformaron la vida económica de Andalucia ${ }^{29}$. Los autores de la época lamentaban el lujo dispendioso de los comerciantes gaditanos, su imitación de las formas de vida noble y su integración en el sistema de valores aristocráticos.

Fue una característica de la centuria el fortalecimiento de la burguesía mercantil en el área cantábrica, gracias a un renovado ímpetu del comercio $^{30}$. En Bilbao se desarrolló un poderoso grupo de comerciantes, relacionados con grandes proyectos de reforma económica y de política estatal (los Gossens, Nafarrondo, Gómez de la Torre, etc.) ${ }^{31}$. Santander contaba a principio del $\mathrm{xIX}$ con más de un centenar de comerciantes y con representantes de las principales compañias por acciones del reino ${ }^{32}$. En cuanto a Galicia se pueden delimitar distintas áreas; Vigo contaba con una cuarentena de comerciantes y navieros. En la Galicia Cantábrica, Vivero y Ribadeo eran puertos activos, con una veintena de comerciantes y una cierta vitalidad industrial ${ }^{33}$. En la Coruña se ha observado el desarrollo de tres generaciones burguesas; el número de comerciantes había triplicado a fines de siglo. Parte de ellos se habian enriquecido con el comercio con América (permitido a La Coruña desde 1764), pero también se transformaban en grandes propietarios rurales. Uno de ellos era Jerónimo de Hinojosa negociante de lonja cerrada, asentista y naviero, fundador de una compañía de seguros marítimos. A una generación posterior perteneció el bearnés Juan Francisco Barrio d'Abadie. En la Galicia cantábrica se desarrolló la actividad del asturiano Antonio Raimundo Ibáñez, en quien debemos destacar dos grandes ras-

${ }^{29}$ Antonio Garcia Baquero: Cádiz y el Atlántico 1718-1776. Sevilla 1976. I.

30 A. ZaVALA: La función comercial del País Vasco en el siglo XVIII, (1983). El comercio y el tráfico marítimo del norte de España en el siglo XVIII, 2 vols. Donostia 1983.

${ }^{31}$ R. BAsurto: Comercio y burguesia mercantil de Bilbao en la segunda mitad del siglo xVIII, Bilbao 1983.

${ }^{32}$ Almanack Mercantil, cit. 273.

${ }^{33}$ MeIJIDE PARDo: Economía marítima en la Galicia cantábrica en el siglo XVIII, Valladolid 1980. Pegerto SaAvedra: Economía, política y sociedad en Galicia. La provincia de Mondoñedo 1480-1830. La Coruña 1985, p. 344 y ss. 
gos económicos: 1) Su relación con el sistema político y social del Antiguo Régimen (arrendatario de diezmos, contrata de municiones) y 2) su actividad industrial (en la siderurgía, pero también en otros sectores, como la cerámica y el vidrio) ${ }^{34}$.

En las islas Canarias se consolidó una burguesía estrictamente comercial, muy especulativa, basada en la exportación de vinos y la importación de productos manufacturados. Los beneficios del comercio se reinvertian en el propio sector. El capital estaba poco diversificado y ofrecia una gran fragilidad ${ }^{35}$.

Los productos objeto del tráfico nos revelan la estructura deficitaria de la balanza mercantil española a lo largo de la Edad Moderna. Se exportaban productos naturales, fundamentalmente lana y vino, también mineral de hierro en el País Vasco, así como otras fibras vegetales según las regiones (seda y esparto en el litoral levantino y en el sureste). Se importaban productos elaborados, entre ellos tejidos, pero también productos naturales, destinados a la alimentación, como los granos o cereales y la pesca salada. El ejemplo del comercio de Valencia en el Almanak mercantil, nos confirma la existencia de estas líneas fundamentales, matizada por circunstancias concretas como eran la importancia de la industria sedera. Aparte de los comerciantes que hacian inversiones industriales, "manteniendo de su cuenta muchos telares", nos encontramos 1) Con la exportación de productos agropecuarios o "géneros del pais" (lana, vino, aguardiente, madera), 2) la importación de productos textiles extranjeros ("lanería y lencería"), 3) la redistribución de productos coloniales (azúcar, cacao) ${ }^{36}$.

La división que acabamos de hacer, aunque indicativa de algunos de los principales ámbitos de actuación de la burguesia, es arbitraria, porque una característica fundamental del comerciante del Antiguo Régimen era su polivalencia, es decir, su falta de especialización en un tipo de comer-

${ }^{34}$ Sobre estos personajes véase los trabajos de MEIJIDE PARDo: "Un hombre de negocios en La Coruña deciochesca" en Revista del Instituto José Cernide, III, 1967. "Un capitán de industria en la Galicia del antiguo régimen", en Anuario de Historia Económica y Social, II, 1968, 461-522 y Documentos para la Historia de la fábrica de Sargadelos, La Coruña 197 .

${ }^{35}$ Agustín Guimera Ravina: Burguesía extranjera y comercio atlántico. La empresa comercial irlandesa en Canarias (1703-1771). Santa Cruz de Tenerife 1985.

${ }_{36}$ Almanak Mercantil, 1806, p. 320. "Lista de las casas de comercio establecidas en esta plaza... distribuidas en clases de diferentes giros según las principales que se les ven hacer". 
cio, producto o actividad determinada. El comerciante se definia por tratar en toda clase de productos, sin limitación de país, ni de cantidad. Durante el primer tercio de siglo, Miguel de Zavala Auñon caracterizaba como comerciantes o mercaderes.

"los que por mar o tierra hacen venir de cualquier género que sea para vender al por mayor 0 al grueso ${ }^{37} "$.

La diferenciación del comercio al mayor y al menor constituía un elemento fundamental en la organización social e institucional de la burguesía del Antiguo Régimen ${ }^{38}$. En el siglo XVIII se continuaba distinguiendo a los «mercaderes de lonja de los mercaderes de vara". Los primeros llamados a veces lonjistas, eran los verdaderos comerciantes o negociantes, caracterizados por el ejercicio de su actividad en tienda cerrada, lonja o almacén. Este "trato y negociación" superior eran los únicos que habilitaban para el ingreso en los consulados de comercio, de los que quedaban excluidos los comerciantes al por menor o mercaderes de tienda abierta. Sólo los consulados fundados en los años 1784-1786 admitieron la entrada de comerciantes al por menor con la denominación especifica de mercaderes.

El segundo nivel social estaba constituido por quienes se dedicaban (por lo menos en teoría) al comercio de un tipo concreto de productos, (mercaderes de paños, de sedas, etc.) y lo hacian al por menor "vareando", es decir, midiendo los tejidos con una vara. Estos dos niveles mercantiles tenian distinta valoración social. Ya a lo largo del xVII, tratadistas y políticos reconocian la compatibilidad del comercio con la nobleza, si aquel se realizaba al por mayor:

"Si el trato es calificado y en cosas grandes y lo más fuera del reino, la cantidad copiosa y en diferentes tratos".

Por el contrario eran incompatibles con una condición honorable quienes:

${ }^{37}$ Representación al Rey nuestro señor don Felipe $V$, Madrid 1732, pp. 49-50.

${ }^{38}$ Véanse las referencias a MOLAs, Burguesia... 46-52. 
"hayan tenido tienda pública de trato y mercancia, vendiendo por menudo o a la vara".

En el siglo XVIII se ahondó la distancia entre los dos niveles del comercio. A fines de siglo, la palabra tendero había adquirido una connotación peyorativa en la pluma de funcionarios y grandes comerciantes. Sin embargo, los comerciantes al por menor (llamados en Cataluña betiguars) tuvieron una actividad económica notable que muchas veces trascendia los estrechos límites corporativos. Cubrian un espacio entre los lonjistas y los artesanos. Socialmente formaban una élite corporativa de gremios mayores. Se dedicaban a la venta de productos de calidad y precio, considerados "trato lucroso". En primer lugar encontramos el comercio de tejidos dividido en dos grandes especialidades: 1) La pañería o comercio de tejidos de lana y 2) la mercería que englobaba los tejidos de seda y lienzo, y una amplia gama de productos, que comprendía medias, sombreros, papel... e incluso colorantes ${ }^{39}$. Un segundo campo de venta era cubierto por los drogueros, o mercaderes de especias; se dedicaban a la comercialización de los productos que por su procedencia se denominaban "coloniales" o "ultramarinos" (azúcar, cacao, etc.). El nivel gremial del pequeño comercio se organizó en diversas ciudades entre 1762 y 1777 con el nombre de "cuerpos generales de comercio". En Murcia se realizó una tentativa en el mismo sentido, después de la guerra de Independencia ${ }^{40}$.

El nivel superior del comercio estaba representado por el giro, es decir por la utilización de letras de cambio, y en suma por las finanzas. El ya citado Zavala Auñón señalaba al "banquero y negociante en cambio y giro", como una especialidad distinta del comercio propiamente dicho. El uso de letra de cambio era factor a tener en cuenta para ingresar en la matrícula de un consulado. En caso de duda, el interesado podía alegar la utilización de giro de letras "como lo practican los comerciantes al por mayor o banqueros" ${ }^{41}$.

Se suele considerar que la existencia del giro en una población es indicativo de la madurez e intensidad de su movimiento mercantil ${ }^{42}$. De

${ }^{39}$ Ibidem, 67-80. Los merceros compartian la venta del amplio campo de la «quincallería", con otros gremios menores, como eran en Barcelona los ferreteros.

${ }_{40}$ Ibidem, 94.

4 MOLAS, Ibidem, 63; Comerç, 46, 378.

42 Dominguez Ortiz: Sociedad y estado en el siglo XVIII español, Barcelona 1976, pp. 243, (Zaragoza). Pierre VILAR: Catalunya dins l'Espanya Moderna. IV La formación del capital comercial, Barcelona 1968, pp. 205. 
todas formas la pequeña burguesía de los mercaderes de vara también practicaba el giro de letras ${ }^{43}$. El conocimiento de letras de cambio y vales era exigido a los aspirantes a entrar en gremios de mercaderes al por menor. Dentro de la pequeña burguesía eran importantes los gremios de compradores de lonja, que a veces se titulaban explícitamente corredores de cambio ${ }^{44}$.

A partir de 1770 se desarrollaron las compañias de seguros por acciones en Barcelona y Madrid ${ }^{45}$ dirigidas e integradas por los principales miembros de la alta burguesía.

La burguesía del Antiguo Régimen tenía una escasa actividad industrial. Conocemos la importancia de la industria naval dispersa en la España del $X V I I I{ }^{46}$. Algunos ejemplos de fines de siglo y principios del XIX nos mostraria la importancia que conservaba la producción dispersa. Jovellanos describe muy bien la organización gremial de la industria de armas de Guipúzcoa:

"Lo que llaman fábrica de armas no es lo que se cree de ordinario. Varios artistas (artesanos) trabajan... cada uno por si, con sus oficiales ${ }^{47}$ "'.

La palabra fábrica todavia se utilizaba en el Almanack Mercantil de 1806 para designar el conjunto de artesanos de una población, por ejemplo la industria de la seda de Málaga.

${ }^{43}$ Molas Ribalta: Los gremios barceloneses en el siglo XVIII, Madrid 1970, pp. $303-$ 304. Economia i Societat al segle XVIII, Barcelona 1975, pp. 79-80.

${ }^{44}$ Véase el resumen de la tesis de M. ${ }^{2}$ Teresa RodRigo en Pedralbes. Revista d'Historia Moderna número 6, 1980.

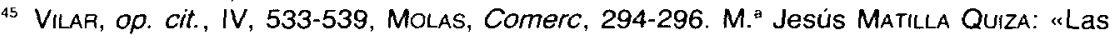
compañias privilegiadas en la España del Antiguo Régimen", en M. ARTOLA: La economia española al final del Antiguo Régimen, IV, Las Instituciones, Madrid 1982, p. 392.

${ }^{46}$ Agustín GONZÁleZ ENCISO: "La Industria dispersa castellana en el siglo XVIII». Cuadernos de Investigación Histórica, $\mathrm{n} .{ }^{\circ}$ 2, 1978, p. 269-289. "La proto industrialización en Castilla la Vieja en el siglo XVII, II Congreso de Historia Económica de Alcalá de Henares, 1981, en Revista de Historia Económica, II, n. ${ }^{\circ}$ 3, 1984, pp. 51-82.

${ }^{47}$ Diarios Selección y prólogo de Julián Marias. Madrid, 1967, p. 46. 
"Compuesto de muchos maestros que se manejan por sí en sus respectivas, el que menos con un telar y otros con más".

- la fabricación de paños en la población andaluza de Grazalema, "en lo que se ocupan muchos vecinos, cada uno de su cuenta aunque formados en gremio" " ${ }^{48}$. La estructura del trabajo en Grazalema era la propia del Antiguo Régimen industrial, con más maestros que oficiales o aprendices ${ }^{49}$. A fines del XVIII y principios del XIX el trabajo disperso se daba en las fábricas de seda de Barcelona ${ }^{50}$, y en la manufactura de algodón de Avila ${ }^{51}$.

La producción artesana se hallaba extendida por muchas ciudades. Véase las iniciativas estatales privadas con protección estatal, que se llevaron a cabo en Valladolid ${ }^{52}$. La Junta general de comercio concedió franquicia y ordenanzas a los gremios textiles de Murcia y Lorca, el Arte Mayor de la Seda o fabricantes de seda, a los fabricantes de paños y otras telas, a los maestros pelaires, tejedores y tundidores de la fábrica de paños y otros tejidos de lana ${ }^{53}$.

Más allá del estadio artesanal encontramos casos de comerciantes que actuaban como empresarios industriales. En un nivel medio podemos citar al negociante de Mataró Mariso Niella, el cual mantenía una fábrica de medias de seda en la ciudad de Murcia ${ }^{54}$. En un nivel superior encon-

48 Almanak Mercantil, p. 346-347.

49 British Libray Eg. 505 f 109, Noticias de los fabricantes de paños y otros tejidos de lana de la Villa de Grazalena».

50 MOLAS RiBALTA: Economia i Societat al segle XVIII, Barcelona 1975 Archivo General de Simancas. Consejo Superior de Hacienda. Leg. $261 \mathrm{n}^{\circ} 3$. Fábrica de tejidos de seda del maestro artesano Francisco Pla. "Tiene corrientes en su casa cinco telares... y suministra seda de su cuenta a quatro maestros del arte, por otros seis telares pagándoles la mano de obra".

51 Archivo General de Simancas. Secretaria de Hacienda. Leg. 756: Repartición de oficinas y máquinas de la Real Fábrica. "Además de los trece telares en esta casa hay otros 127 repartidos por la ciudad... al cargo de 26 oficiales o maestros que tienen 101 aprendices". Véase también el libro de Gonzalo MARTIN GarCias: Nacimiento de una industria textil en Avila en el siglo xvill. La Real Fábrica de Algodón (1787-1792), Avila 1983.

52 Agustín GonzALEz ENCISO: La Industria vallisoletana del Setecientos en Valladolid en el siglo XVIII. Tomo V de la Historia de Valladolid, Valladolid 1984, pp. 263-290.

53 AGS Consejo Supremo de Hacienda. Libro 248 fols. 260-301. Sobre los gremios, Juan Garcia ABellan, Organización de los gremios en la Murcia del siglo XVIII. Murcia 1976. Sobre la seda Pedro Olivares: El Cultivo y la Industria de la seda en Murcia en el siglo XVIII, Murcia 1976.

54 Archivo de la Corona de Aragón. Archivo Notarial de Mataró. Leg. 653 e/ f (1741). 
tramos al financiero Goyeneche, empresario industrial textil y de vidrio en el Nuevo Baztam y otras poblaciones de los alrededores de Madrid ${ }^{55}$. En la pañería de Segovia se produjo una concentración de los medios de producción por la inversión del capital comercial, sobre todo en la figura de Laureano Ortiz de Paz ${ }^{56}$.

En Granada merece destacarse la acción de Juan Andrés Gómez en la fabricación de lanas y lienzos en los años posteriores a $1778^{57}$. En la construcción naval metalurgía tenemos a personajes como Fernández de Isla en Santander ${ }^{58}$. Antonio Raimundo Ibáñez, marqués de Sagardelos ${ }^{59}$ o los sucesivos propietarios de la fábrica de hojalata de Ronda ${ }^{60}$.

En el A/manak Mercantil de 1806 encontramos diversos ejemplos de posible organización industrial en el área cantábrica. Tenemos la organización gremial de las "fábricas reales de fusiles, escopetas y pistolas" en Guipúzcoa, la empresa plenamente estatal en los Altos Hornos de Liérganes ${ }^{61}$ y la Caveda, "de cuenta de Su Magestad", la empresa privada con privilegios en la fábrica real de sombreros finos de Juan Francisco Parrié, y el aristócrata como empresario industrial en la fábrica de algodones del duque del Infantado en Torrelavega.

Dada la importancia que tuvieron en la industria española del siglo XVIII las empresas estatales, sugiero el interés de considerar el papel de los directores de tales fábricas. No eran empresarios capitalistas, puesto que no invertían capitales. Eran funcionarios de la administración, o técnicos privilegiados por la misma, que dirigian importantes conjuntos fabriles. Deberían ser tenidos en cuenta en el estudio sobre la actividad económica de la burguesia. Me referiré tan sólo a unos casos: los direc-

${ }^{55}$ Caro Baroja: La hora navarra, 2. ${ }^{a}$ edición, 1985. Capítulo V.

56 Ángel Garcia Sanz: Desarrollo y crisis del Antiguo Régimen en Castilla la Vieja. Economia y Sociedad en Tierras de Segovia. 1500 1814, Madrid 1977, p. 220 y ss.

57 AGS CSH Libro 247, fols 57 y ss. MOLAS Ribalta, "Las Juntas de Comercio de Andalucia (S. XVIII)" en Actas del I Congreso de Historia de Andalucia. Andalucia Contemporánea, Córdoba 1979, I pp. 159-170.

${ }^{58}$ Callaham William J.: Comerce and Industry in eighteenth century Spain, Boston, 1972, p. 23-24. José P. MeRINo: La Armada española en el siglo XVIII, Madrid 1981, p. 95 , $n^{\circ} 61,193-4,301$.

59 Meluide Pardo: Documentos... op. cit..

60 José AlCALA ZamORA: “Progresos tecnológicos y limitaciones productivas en la nueva siderurgia productiva del siglo XVIII", Hispania, 1977. 379-414.

${ }^{61}$-: Historia de una empresa siderúrgica espñola. Las fábricas de Liérganes y la Cavada 1622-1834, Santander 1974. 
tores de la Real Fábrica de Paños de Guadalajara ${ }^{62}$, los directores y altos técnicos especializados de las fábricas propiedad de los Cinco Gremios Mayores de Madrid, por ejemplo la fábrica de sedas de Valencia ${ }^{63}$, los directores de la manufactura de algodón de Avila, Agustín de Bethancourt y Diego M. ${ }^{a}$ Gallard, ambos vinculados a otras facetas del reformismo económico ${ }^{64}$. $Y$ en el plano financiero encontramos a los altos funcionarios que gestionaron el edificio de la deuda pública durante el reinado de Carlos IV, como Manuel Sixto Espinosa, uno de los dirigentes del Banco de San Carlos, de la Compañía de Filipinas, del consejo de hacienda, de la junta general de comercio, etc. ${ }^{65}$.

La sedería de Valencia dio lugar a una considerable burguesia, con muchas connotaciones artesanales. Las ordenanzas de los cuerpos de comercio (1765) permitían el ingreso de los fabricantes de lana y seda. Pero ¿qué debemos entender bajo el nombre de fabricante? Podia tratarse de un comerciante dedicado en mayor o menor grado a la industria. Pero era más frecuente el caso de los artesanos acomodados que, sin abandonar totalmente las filas del gremio, del Arte Mayor de la Seda, llegaron a equipararse con los comerciantes ${ }^{66}$. Tenemos buena prueba en los empresarios que llegaron a obtener un privilegio de nobleza. Vicente Tamarit era considerado como un ufabricante, director y comerciante", miembro del Arte Mayor, de cuya matricula nunca había intentado borrarse. A Félix Pastor la riqueza obtenida.

"Jamás le inclinó a abandonar la ocupación de fabricante de seda".

Pero por supuesto se diferenciaban claramente las funciones de los meros artesanos ("que trabajan y laboran por sus mismas manos") y de los empresarios que

"poseyendo un crecido caudal... se dedican con afán y desvelo a los texidos... no exerciendo por si mismos, lo mecánico de estas artes y

62 A. González EnCISO: Estado e industria en el siglo XVIII. La fábrica de Guadalajara, Madrid 1980.

so MOLAS: Burguesía..., 216.

${ }^{64}$ - : "De la Junta de Comercio al Ministerio de Fomento", en Actas N Simposio $H^{\text {. }}$ Administración, Alcalá de Henares, 1983, 537-546.

${ }^{65}$ Guia de Forasteros, 1804, pp. 90-97.

66 MOLAS: Burguesia, 213-214 y 221-224. 
manufacturas... y prestando un manejo, no material sino de dirección y protección que nada tienen de mecánico ${ }^{67}$ ".

En la industria de indianas de Cataluña la separación entre el capital y el trabajo fue más radical ${ }^{68}$. Los primeros empresarios de la nueva industria de tejidos de algodón estampados, en torno a 1740, pertenecían a los distintos niveles del comercio. Sin embargo, el papel principal correspondia al fabricante, es decir el técnico que conocía los procedimientos del estampado y se encargaba con frecuencia de la dirección del trabajo de los tejedores. En el decenio de 1750 se formaron nuevas compañías, con participación de artesanos acomodados, en especial de maestros o fabricantes de tejidos de seda ${ }^{69}$.

Cuando, a partir de 1758 , se crearon en Barcelona los cuerpos de comercio, la burguesia de Barcelona era básicamente comerciante e incluía pocos empresarios algodoneros. Se mantenía todavía la diferencia entre los "dueños de fábrica" y los fabricantes; sólo en casos minoritarios coincidian ambas condiciones. Cuando la burguesia industrial fundó su primera institutición colectiva, la Compañía de Hilados de Algodón (1772) sólo un 39 por 100 de sus socios pertenecian a la matrícula del comercio. El empresario, que contaba con mayor número de telares, era un antiguo fabricante o socio técnico de una compañia dirigida por un mercader.

El crecimiento cuantitativo de la industria potenció el peso de los empresarios industriales en el conjunto de la sociedad. En 1779 se contaban unas 70 fabricas, en 1790 había cerca de un centenar. A partir de 1783 los fabricantes de indianas y "lienzos pintados" eran considerados como un grupo fiscal distinto al del comercio propiamente dicho. La proporción entre ambos sectores económicos quedó establecida en 2 a 1 en favor del comercio. Los nuevos empresarios ya no procedian del comercio o de los gremios, como en las etapas iniciales, sino de la propia industria. Cada vez con mayor frecuencia los fabricantes o técnicos del estampado se convertian al cabo de pocos años en empresarios independientes. Un comerciante podía y solía repartir sus inversiones industriales en diversos sectores. En Mataró José Cantallops no sólo tenía un impor-

\footnotetext{
${ }^{67}$ Ibidem, 234-237.

68 lbidem, 238 y ss.

69 Molas: Los gremios, 52. Burguesia, 241-242.
} 
tante almacén de telas, sino que realizaba inversiones en los siguientes sectores industriales: 1) Indianas, 2) sedas y 3) curtidos $^{70}$. Seria interesante realizar un estudio de las manufacturas de estampados que se intentaron establecer en diversos lugares de España, por ejemplo, en Puerto de Santa Maria, Madrid, Alicante, Tarazona de la Mancha, etc.

Durante la primera mitad del siglo proliferaron los proyectos de compañías privilegiadas por acciones ${ }^{71}$, para el comercio con América. Solo en tres cascos se llegó a la práctica (Guipuzcoana o de Caracas 1728, La Habana, 1740 y Barcelona, 1756). Hubo también las compañías de "comercio y fábricas", fundadas en 1746-1748 en Aragón, Toledo, Extremadura, Granada y Sevilla, durante el ministerio de Carvajal. El mismo ministro redactó un proyecto para que todas las regiones españolas, incluso las interiores, tuvieran una compañía para el comercio de India; en esta distribución, Chile correspondia a Murcia, Cartagena y Orihuela ${ }^{72}$. Las compañias privilegiadas no eran sólo empresas, sino también organismos de representación social de la burguesia; los propagandistas de tales instituciones (Miguel de Zavala, por ejemplo), situaban el honor como un elemento importante de las mismas.

Durante la segunda mitad del siglo, la burguesía se organizó en consulados de comercio. En 1737 se promulgaron nuevas ordenanzas del consulado de Bilbao y se les dio vigencia como ley mercantil para toda España $^{73}$. En 1758-62 se restauraron los consulados de Barcelona y Valencia, y en 1766 se renovaron las ordenanzas de Burgos y S. Sebastián. En los años siguientes, los puertos de Alicante y Santander obtuvieron una institución consular autónoma. Los consulados creados a partir de la libertad de comercio con América (1778) reunian a hacendados, comerciantes al por mayor y menor, fabricantes y mercaderes. La normativa reconocía el menor desarrollo de la industria, puesto que el capital exigido a los fabricantes para ser aceptados en la matrícula era un 50 por 100 y hasta un 75 por 100 inferior a los comerciantes. El número de «fabricantes» era notoriamente inferior que el de comerciantes en todos los consulados ${ }^{74}$.

70 -: Societat, 44.

7 Matilla Quiza: Citada.

72 José DE CARVAJAL: "Testamento Político" en Almacén de frutos literarios. Madrid 1818,11 , p. 134. «Para el reino de Chile solo, situada en algún puerto que se fortique en Murcia, no siendo en Cartagena, y darle a Murcia, Cartagena y Orihuela".

${ }^{73}$ Carlos PETIT: La compañia mercantil bajo el régimen del consulado de Bilbao, 17371829, Sevilla 1979.

${ }_{74}$ MOLAS: Burguesía, 56-65. 
La legislación era favorable a la participación de la nobleza en el comercio y en la industria (desde 1682). Las ordenanzas de las compañias privilegiadas y de los consulados estimulaban la inversión nobiliaria afirmando que no produciría mácula alguna de su condición, antes bien sería causa de un «renovado lustre y esplendor» ${ }^{75}$. Más aún el comercio y la industria ejercicios a lo largo de tres generaciones se convirtieron en motivo de ennoblecimiento con la real cédula de marzo de 1783, que proclamaba la honorabilidad del trabajo manual ${ }^{76}$. En los años siguientes los aspirantes al ennoblecimiento alegaban explícitamente sus méritos industriales (“aplicación a la fábrica de tejidos y pintados, por ejemplo) ${ }^{77}$. Una generación más adelante en 1817, las ordenanzas del Consulado de Granada se mostraban favorables a los fabricantes:

“labricantes que manegen personalmente sus máquinas y telares... se tendrá por un mérito particular esta laboriosidad como la más conforme a los principios de la economia ${ }^{78}$.

No es difícil encontrar en los principales puertos ejemplos de comerciantes ennoblecidos, como el marqués de la Colonilla en Bilbao ${ }^{79}$, los comerciantes gaditanos, o los catalanes que constituían el 16 por 100 de los nuevos nobles del Principado, algunos aristócratas tuvieron un papel como empresarios industriales: el duque de Bejar en la industria textil, el conde de Aranda en la cerámica, etc. En 1789 el duque de Osuna encabezaba la junta de suscriptores de una compañía de seguros terrestre y marítima $^{80}$.

Sin embargo, seguian existiendo prejuicios sociales contra la actividad mercantil. "Parece que el comerciar debilita la nobleza" lamentaba a principios del XIX en Valencia un marqués de origen burgués descontento de que se le tratara "como a cualquiera del estado llano" ${ }^{81}$. La integración era más difícil de conseguir para el industrial que para el

\footnotetext{
75 Ibidem, 173-174.

76 Guillamón Álvarez: Honor y honra en la España del siglo xvII. Madrid 1981.

MOLAS: Burguesía, 159.

78 Ibidem, 145.

79 Hay una biografia del mismo por el marqués de Saltillo, Madrid 1932.

${ }^{80}$ A.G.S., C.S.H. Libro 242, fol. 124.

8' MOlas: Burguesía, 230.
} 
comerciante, como muestran algunos ejemplos de la industria textil en Castilla y Cataluña ${ }^{82}$.

Entre la actividad de la burguesía mercantil no parece haber ocupado un lugar preferente la reflexión intelectual teórica sobre problemas económicos. Se decía que los comerciantes gaditanos no conocian más letras que las de cambio, ni más libros que los de caja ${ }^{83}$. Los principales autores sobre cuestiones económicas eran funcionarios y juristas no empresarios. Quizás deba hacerse una excepción con Juan B. Loustau, autor de numerosos informes, noticias y proyectos ${ }^{84}$.

La burguesía mercantil se hallaba situada en la jerarquia de la sociedad estamental por debajo de las profesiones universitarias, médicos y juristas. En compensación el comerciante se ufanaba de su formación empírica, "la cual no se aprende con discursos ni se aprende en las universidades" ${ }^{85}$. Los ilustrados criticaron la educación universitaria como ineficaz, pero al mismo tiempo se desarrollo la idea de que la profesión mercantil necesitaba una formación básica. Muchos proyectistas apuntaron la idea de la necesidad de una escuela de comercio ${ }^{86}$. Uno de ellos fue el catalán Juan Francisco Vila, representante en Madrid de una entidad financiera catalana. El autor se hacía eco de la idea predominante a fines de siglo contra las compañías protegidas («compañías públicas de grandes capitales") y exponía la indiferencia de los comerciantes hacia la formación teórica «persuadidos equivocadamente de que les basta la práctica" ${ }^{87}$. La idea de crear "escuelas de comercio" es patente en el reformismo económico a fines del siglo $\mathrm{XVIII}^{88}$.

2. Ibidem, 147-148 y 160.

83 Citado por Domínguez Ortiz: Sociedad y estado, 397, núm. 29.

84 Existen abundantes manuscritos de Lostau en el Archivo Campomanes, en los manuscritos de la British Library y en la sección de estado del Archivo Histórico Nacional.

85 Molas: La burguesía, 182.

${ }^{36}$ A.H.N. Estado. Archivo Campomanes, 37-43.

87 Carrera Pujal: Historia política y económica de Cataluña, IV, 457. Molas: De la Junta de Comercio al Ministerio de Fomento, 532.

8 Archivo Campomanes, 37-43. Escuela de Comercio. Memorias sobre la utilidad de su establecimiento. A.H.N. Estado, leg. 2932, núm. 19.1. Propuesta de fundar una escuela pública de comercio en cada consulado (1785). 